\title{
2002-03 ACRL chapter conferences/events
}

\begin{tabular}{|c|c|c|c|}
\hline Chapter & Date & Description of Event & Location \\
\hline Florida & Oct. 18,2002 & "New Realities, New Opportunities" workshop & Orlando \\
\hline Georgia & Oct. 9-11, 2002 & $\begin{array}{l}\text { Georgia Library Association Annual Conference: } \\
\text { "Building Georgia's Learning Communities" }\end{array}$ & Athens \\
\hline Indiana & Apr. 14-16, 2003 & Indiana Library Association Annual Conference & Indianapolis \\
\hline Iowa & $\begin{array}{l}\text { Oct. } 9-11,2002 \\
\text { May } 1-2,2003\end{array}$ & $\begin{array}{l}\text { Iowa Library Association Annual Conference: } \\
\text { "Where's the Evidence? Discovering the Measures } \\
\text { that Make Up a Library's Contribution to Student } \\
\text { Leaming Outcomes" } \\
\text { Iowa Library Association Spring Conference }\end{array}$ & Des Moines \\
\hline Kansas & Oct. $10-11,2002$ & $\begin{array}{l}\text { The Fall College and University Library Section } \\
\text { of the Kansas Library Association Annual } \\
\text { Conference } \\
\text { The College and University Library Section of } \\
\text { the Kansas Library Association Annual Tri- } \\
\text { Conference }\end{array}$ & Salina, KS \\
\hline Kentucky & Oct. $16-19,2002$ & $\begin{array}{l}\text { Kentucky Library Association Annual Conference: } \\
\text { "Get the Professional Juices Flowing @ your } \\
\text { Library" }\end{array}$ & Louisville \\
\hline Mississippi & Oct. 16,2002 & $\begin{array}{l}\text { Mississippi Library Association Annual Meeting: } \\
\text { "Soft Skills: Creating a Better Workplace" }\end{array}$ & Hattiesburg \\
\hline Nevada & Nov. $4-8,2002$ & $\begin{array}{l}\text { The Mountain Plains Library Association and } \\
\text { the Nevada Library Association joint conference }\end{array}$ & Iake Tahoe \\
\hline $\begin{array}{l}\text { New York } \\
\text { (Eastern) }\end{array}$ & Oct. $17-18,2002$ & Eastern New York/ACRL Annual Fall Conference & Syracuse \\
\hline $\begin{array}{l}\text { New York } \\
\text { (Metro) }\end{array}$ & Nov. 15,2002 & $\begin{array}{l}\text { Annual Symposium: "What's in a Name? Defining } \\
\text { Our Profession" }\end{array}$ & $\begin{array}{l}\text { New York } \\
\text { City }\end{array}$ \\
\hline Ohio & Nov. 1,2002 & $\begin{array}{l}\text { Ohio Library Association Annual Conference: } \\
\text { "Face to Face or Cyberspace: Redefining the } \\
\text { Human Touch" }\end{array}$ & Independence \\
\hline Oregon & Apr. $23-25,2003$ & Oregon Library Association Annual Conference & Portland \\
\hline Tennessee & Apr. 3-4, 2003 & Tennessee Library Association Annual Conference & Chattanooga \\
\hline Utah & May $7-9,2003$ & Utah Library Association Annual Conference & Sandy, UT \\
\hline Wisconsin & Apr. $5-8,2003$ & Wisconsin Library Association Annual Conference & Milwaukee \\
\hline
\end{tabular}

